\title{
Synthesis of silver nanoparticles from stem bark of Cochlospermum religiosum (L.) Alston: an important medicinal plant and evaluation of their antimicrobial efficacy
}

\author{
A. Sasikala $\cdot$ M. Linga Rao $\cdot$ N. Savithramma $\cdot$ \\ T. N. V. K. V. Prasad
}

Received: 19 September 2014/ Accepted: 12 November 2014/Published online: 25 November 2014

(C) The Author(s) 2014. This article is published with open access at Springerlink.com

\begin{abstract}
The use of different parts of plants for the synthesis of nanoparticles is considered as a green technology as it does not involve any harmful chemicals. Herein, we report on rapid biosynthesis of silver nanoparticles (SNPs) from aqueous stem bark extract of Cochlospermum religiosum a medicinal plant. The reduced silver nanoparticles were characterized by using UV-Visible spectroscopy (UV-Vis), X-ray diffraction (XRD), scanning electron microscopy (SEM), energy dispersive X-ray analysis, atomic force microscopy, and Fourier transform infrared (FT-IR). The UV-Visible spectrum of the aqueous medium containing silver nanoparticles showed an absorption peak at around $445 \mathrm{~nm}$, XRD showed that the particles are crystalline in nature, with a face-centered cubic structure and the SEM images showed that the spherical-shaped silver nanoparticles were observed and the size range was found to be $20-35 \mathrm{~nm}$. FT-IR spectroscopy analysis revealed that carbohydrate, polyphenols, and protein molecules were involved in the synthesis and capping of silver nanoparticles. These phytosynthesized SNPs were tested for their antimicrobial activity and it analyzed by measuring the inhibitory zone. Cochlospermum religiosum aqueous stem bark extract of SNPs
\end{abstract}

Electronic supplementary material The online version of this article (doi:10.1007/s13204-014-0380-8) contains supplementary material, which is available to authorized users.

A. Sasikala $\cdot$ M. Linga Rao $\cdot$ N. Savithramma Department of Botany, S.V. University, Tirupati 517502, A.P., India

T. N. V. K. V. Prasad ( $\square)$

Nanotechnology laboratory, Institute of Frontier Technology,

Regional Agricultural Research Station, Acharya N G Ranga

Agricultural University, Tirupati 517502, A.P., India

e-mail: tnvkvprasad@gmail.com showed highest toxicity to Staphylococcus followed by Pseudomonas, Escherichia coli and Bacillus and lowest toxicity towards Proteus. Whereas in fungal species highest inhibition zone against Aspergillus flavus followed by Rhizopus, Fusarium, and Curvularia, and minimum inhibition zone was observed against Aspergillus niger species. The outcome of this study could be useful for the development of value added products from indigenous medicinal plants of India for nanotechnology-based biomedical applications.

Keywords Cochlospermum religiosum - Antimicrobial activity $\cdot$ Scanning electron microscopy (SEM) - Stem bark extract $\cdot$ Fourier transform infrared (FT-IR)

\section{Introduction}

In recent years, nanotechnology has been emerging as a rapidly growing field with numerous applications in science and technology for the purpose of manufacturing new materials (Savithramma et al. 2011). This technology is defined as the design, characterization, and application of structures, devices, and systems by controlling shape and size at nanometer scale level $(1-100 \mathrm{~nm})$. Nanoparticles are being viewed as fundamental building blocks of nanotechnology and defined as particles having one or more dimensions in the order of $100 \mathrm{~nm}$ or less. The most important and distinct property of nanoparticles is that they exhibit larger surface area-to-volume ratio. Among the nanoparticles studied so far, extensive research has been done on silver nanoparticles (Ag NPs) keeping in view of their potential bio-medical applications. Historically, silver metal has been used widely across the civilizations for different purposes. Many societies use silver as jewelry, 
ornamentation, and fine cutlery. Silver jewelry, wares, and cutlery were considered to impart health benefits to the users. There is an increasing use of silver as an efficacious antimicrobial agent in wound care products and medical devices (Kim et al. 2007; Shahverdi et al. 2007). Silver compounds are utilized as therapeutic modalities for wound management due to their biocidal activities toward a wide spectrum of microorganisms and their anti inflammatory effects (Tian et al. 2001; Liu et al. 2010) by contrast, the silver ion compounds may have cytotoxic effects and impair the wound healing process (Vanderplas et al. 2008). Production of nanoparticles can be achieved through different chemical methods like thermal decomposition of silver compounds (Plante et al. 2010), radiation assisted (Cheng et al. 2011) electro chemical (Hirsch et al. 2005) and recently green chemistry method (Ankamwar et al. 2005). Biological method, there is no need to use high pressure, energy, temperature, and toxic chemical that may have adverse effect in the medical applications (Nagajyothi et al. 2012). A number of living organisms are already well known to elaborate nanostructured composites such as cyanobacteria, bacteria, fungi, antinomycetes, biomolecules, and various plant materials such as Svensonia hyderobadensis (Lingarao and Savithramma 2012), Shorea tumbuggaia (Venkateswarlu et al. 2010) and Thespesia populnea (Bhumi et al. 2013), Ocimum tenuiflorum, Solanum tricobatum, Syzygium cumini, Centella asiatica, and Citrus sinensis (Logeswari et al. 2012). The potential of the plants as biological materials for the synthesis of nanoparticles is currently under exploitation. Hence the present study aimed to green synthesis of silver nanoparticles from stem bark extract of Cochlospermum religiosum (L) Alston and evaluation of their antimicrobial activity.

Cochlospermum religiosum (L) Alston is a sparsely branched small tree, belonging to the family Cochlospermaceae. It is commonly called as Yellow Silk Cotton, Buttercup Tree, and Torchwood Tree because of flowers are large, bright golden yellow, and seeds covered with silky hairs. Cochlospermum religiosum stem bark and root powder is traditionally used for fertility and ash of fruit mixed with coconut is used for the treatment of scabies (Goud et al. 2005). The gum of $C$. religiosum is also found to be an ingredient of unani medicine Qurs-e-Sartaan Kafoori which is used for Styptic, Antipyretic, Phthisis, Tuberculosis, Hectic fever, and Qurs-e-Suzak Cicatrizant, Diuretic, Gonorrhea. These formulations were found to possess good antibacterial and antifungal activity (Cecilie et al. 2005). Sasikala and Savithramma (2012a, b, c) studied the antimicrobial activity of biological synthesis of silver nanoparticles from leaves of $C$. religiosum and also studied the quantitative and quantification of phytochemicals (Sasikala and Savithramma 2012a, b, c; Sasikala et al. 2013a, b), in vitro propagation (Sasikala and Savithramma 2012a, b, c) and Histochemical (Sasikala et al. 2013a, b).

\section{Materials and methods}

All the chemicals and reagents used in the present study were of analytical grade. Silver nitrate was purchased from Sigma-Aldrich chemicals. The glassware were washed in dilute nitric acid and thoroughly washed with double distilled water and dried in hot air oven.

Preparation of plant extract

Cochlospermum religiosum stem bark was collected from Tirumala hills of Andhra Pradesh, India. The barks were washed thoroughly thrice with distilled water and were shade dried for 10 days. The fine powder was obtained from dried leaves using kitchen blender. The bark powder was sterilized at $121^{\circ} \mathrm{C}$ for $5 \mathrm{~min} .5 \mathrm{~g}$ of powder were taken into $250 \mathrm{ml}$ conical flask and added $100 \mathrm{ml}$ of sterile distilled water and boiled for $15 \mathrm{~min}$ at $100{ }^{\circ} \mathrm{C}$. Then the bark extract was collected in separate conical flask by standard filtration method.

Synthesis of silver nanoparticles

$1 \mathrm{mM} \mathrm{AgNO}{ }_{3}$ solution was prepared and stored in amber color bottle. The bark extract was added to $1 \mathrm{mM} \mathrm{AgNO}_{3}$ solution. The color change of the solution from yellow to brown indicated the silver nanoparticles were synthesized from the bark for the characterization and antimicrobial activity.

\section{$\mathrm{UV}-\mathrm{Vis}$ spectra analysis}

The reduction of pure silver ions was monitored by measuring the UV-Vis spectrum of the reaction medium at $5 \mathrm{~h}$. After diluting, a small aliquot analysis was done using UVVis spectrophotometer UV-2450 (Shimadzu).

X-ray diffraction (XRD) analysis

The practice size and nature of the silver nanoparticle were determined using XRD. This was carried out using Shimadzu XRD-6000/6100 model with $30 \mathrm{kV}, 30 \mathrm{~mA}$ with $\mathrm{Cuk} \propto$ radians at $2 \theta$ angle. $\mathrm{X}$-ray powder diffraction is a rapid analytical technique primarily used for phase identification of a crystalline material and can provide information on unit cell dimensions. The analyzed material is finely ground-and average bulk composition is determined. The particle or grain size of the particles on the 
silver nanoparticles was determined using Debye Sherrer's equation,

$\mathrm{D}=\mathrm{k} \lambda / \beta(\operatorname{Cos} \theta)$.

Fourier transform-infrared spectrophotometic (FT-IR) analysis

The functional group of silver nanoparticles was identified by FT-IR using (Thermo Nicolet-nexus 670 spectrometer of resolution $4 \mathrm{~cm}^{-}$) one drop of sample was placed between the plates of sodium chloride. The drop forms a thin film between the plate sodium chloride is transparent to infrared light.

SEM analysis of silver nanoparticles

Scanning electron microscope (SEM) analysis was carried out using Hitachi S-4500 SEM Machine. Thin films of the sample were prepared on a carbon-coated copper grid by just dropping a very small amount of the sample on the grid, extra solution was removed using a blotting paper and then the film on the SEM grid was allowed to dry.

Energy dispersion spectrophotometric (EDS) measurements

In order to carryout EDAX analysis, the drop of bark extract with reduced silver nanoparticles was dried on coated with carbon film and performed on Hitachi S-3400N SEM instrument equipped with thermo EDAX attachments.

Atomic force microscopic (AFM) measurements

The silver nanoparticles extracted through above protocol were visualized with an atomic force microscope. A thin film of the sample was prepared on a glass on the slide was allowed to dry for $5 \mathrm{~min}$, the slides were then scanned with the AFM (Nano Surf ${ }^{\circledR}$ AG, Switzerland, and Product: BTO 2089, BRO).

Evaluation of the antimicrobial activity of silver nanoparticles synthesized using stem bark extract of Cochlospermum religiosum

\section{Microorganisms}

Pure cultures of E. coli, Pseudomonas aeruginosa, Bacillus subtilis, Proteus vulgaris, and Staphylococcus species of bacteria and Fusarium oxysporum, Curvularia lunata, Rhizopus arrhizus, Aspergillus niger, and Aspergillus flavus species of fungi were procured from the Department of Microbiology of Sri Venkateswara Institute of Medical
Science (SVIMS). The experiments of antimicrobial activity were carried out in the Department of Microbiology, Sri Venkateswara University, Tirupati, Andhra Pradesh, India.

\section{Antibacterial activity}

The antibacterial activity of SNPs was carried out by disk diffusion method (Bauer et al. 1966). Nutrient agar medium plates were prepared, sterilized, and solidified. After solidification bacterial cultures were swabbed on these plates. The sterile disks were dipped in silver nanoparticles solution $(10 \mu \mathrm{g} / \mathrm{ml})$ and placed in the nutrient agar plate and kept for incubation at $37{ }^{\circ} \mathrm{C}$ for $24 \mathrm{~h}$. Zones of inhibition for control, SNPs and silver nitrate were measured. The experiments were repeated thrice and mean values of zone diameter were measured with the help of MIC Scale, and the results were tabulated.

\section{Antifungal activity}

Potato dextrose agar plates were prepared, sterilized, and solidified, after solidification fungal cultures were swabbed on these plates. The sterile disks were dipped in silver nanoparticles solution $(10 \mu \mathrm{g} / \mathrm{ml})$ and placed in the agar plate and kept for incubation for 7 days. After 7 days, zone of inhibition was measured with the help of MIC Scale, and the results were tabulated.

\section{Results and discussion}

The time of addition of plant extract into the silver nitrate solution was considered as the start of the reaction. It is well known that the silver nanoparticles exhibit yellowish brown color in aqueous solution due to excitation of Surface Plasmon Resonance. Cochlospermum religiosum bark extract was mixed in the aqueous solution of silver nitrate, initially the color changed from light yellowish to dark brown color (Fig. 1) due to the reduction of silver ion, similar results were observed in various plants studied by Lingarao et al. (2013); Ankanna et al. (2010). Formation and stability of silver nanoparticles in aqueous colloidal solution are confirmed using UV-Vis spectral analysis. The UV-Vis spectrum showed maximum absorbance at $445 \mathrm{~nm}$ (Fig. 2), which increased with time of incubation of silver nitrate with the plants extract. The broadening of peak indicated that the particles are poly dispersed. It has been reported earlier that silver has absorbance at round $430 \mathrm{~nm}$ (Nestor et al. 2008). The presence of the secondary metabolites in plant extract may be responsible for the reduction of silver and synthesis of nanoparticles. The biogenic route is the energy (or) electron released during 


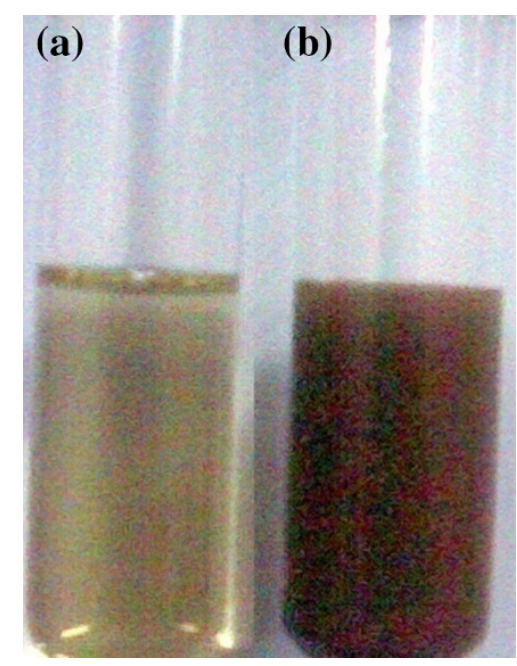

Fig. $1 a$ Plant extract, $b$ plant extract with silver nitrate (SNPs) the color change of stembark extract of $C$. religiosum

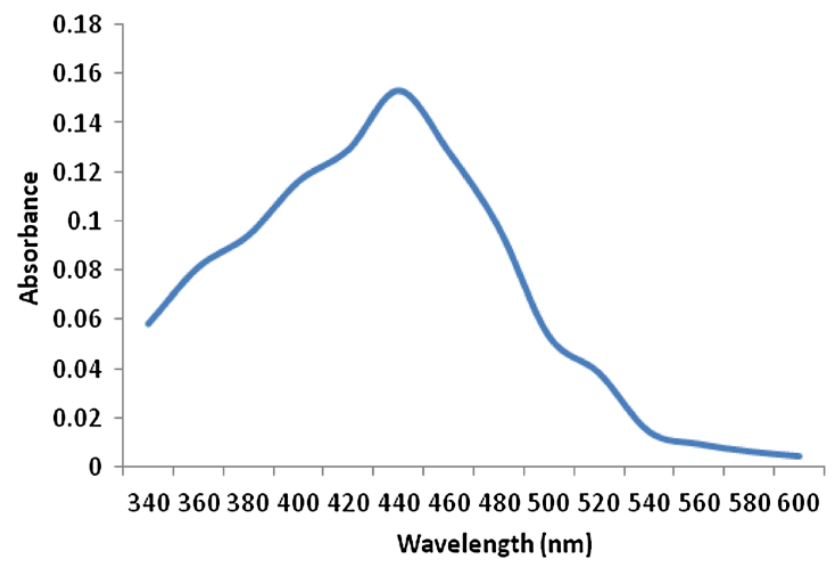

Fig. 2 UV-Visible spectroscopic micrograph showing the characteristic absorbance of $C$. religiosum stem bark-synthesized silver nanoparticles at $445 \mathrm{~nm}$

Glycolysis (photosynthesis) for conversion of NAD to NADH led to transformation of $\mathrm{Ag}\left(\mathrm{NO}_{3}\right)_{2}$ to form nanoparticles and another mechanism is releasing of an electron when formation of ascorbate radicals from ascorbate reduces the silver ions,

$$
\begin{aligned}
& \mathrm{AgNO}_{3} \rightarrow \mathrm{Ag}+\mathrm{NO}_{3} \\
& \mathrm{NAD}^{+}+\mathrm{e} \rightarrow \mathrm{NAD} \\
& \mathrm{NAD}+\mathrm{H}^{+} \rightarrow \mathrm{NADH}+\mathrm{e}^{-} \\
& \mathrm{e}^{-}+\mathrm{Ag}^{+} \rightarrow \mathrm{Ag}^{0} .
\end{aligned}
$$

The XRD pattern showed number of Bragg reflections that may be indexed on the basis of face-centered cubic structure of silver. The XRD analysis is confirmed that the silver particles formed in the experiments were in the form of nanocrystals, as evidenced by the peaks at $2 \theta$ values of $38.28^{\circ}$ and $48.04^{\circ}$ corresponding to (111) and (200) Bragg

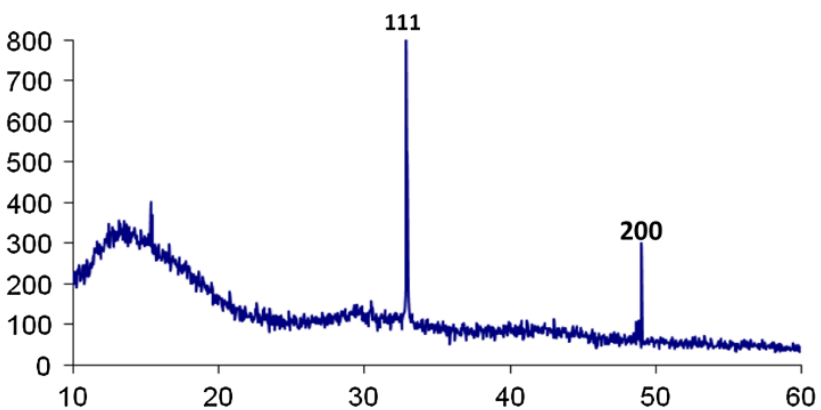

Fig. 3 XRD micrograph showing the Bragg's reflections corresponds to the face-centered cubic (FCC) structure of SNPs synthesized using the stembark of $C$. religiosum

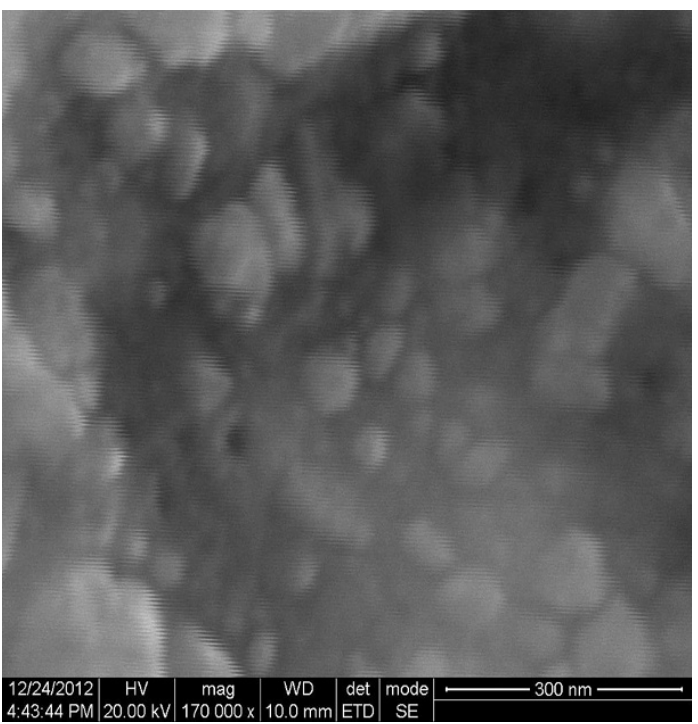

Fig. 4 SEM micrograph revealing the presence of the silver nanoparticles (agglomerated) of synthesized using C. religiosum Stembark

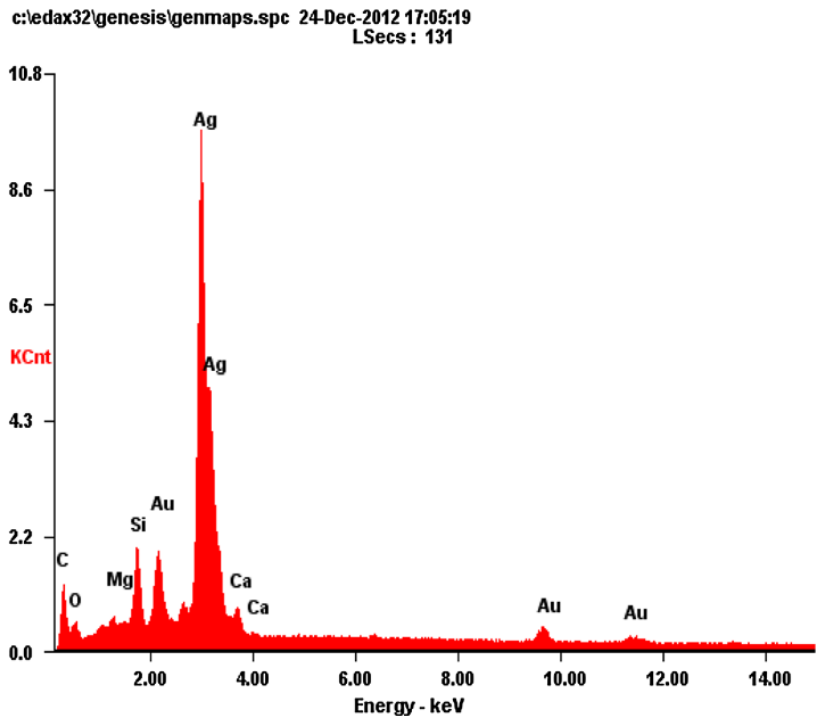

Fig. 5 EDS spectrum evidencing the elemental presence of silver along with calcium, magnesium silicon, oxygen, and carbon 


\section{Nanosurf EZ2-AFM data}

File: E:Isamples|2011|JUN-2011|30-06-2011-Bark-SVuniversity-TirupathylL2IL2c-15um.nid

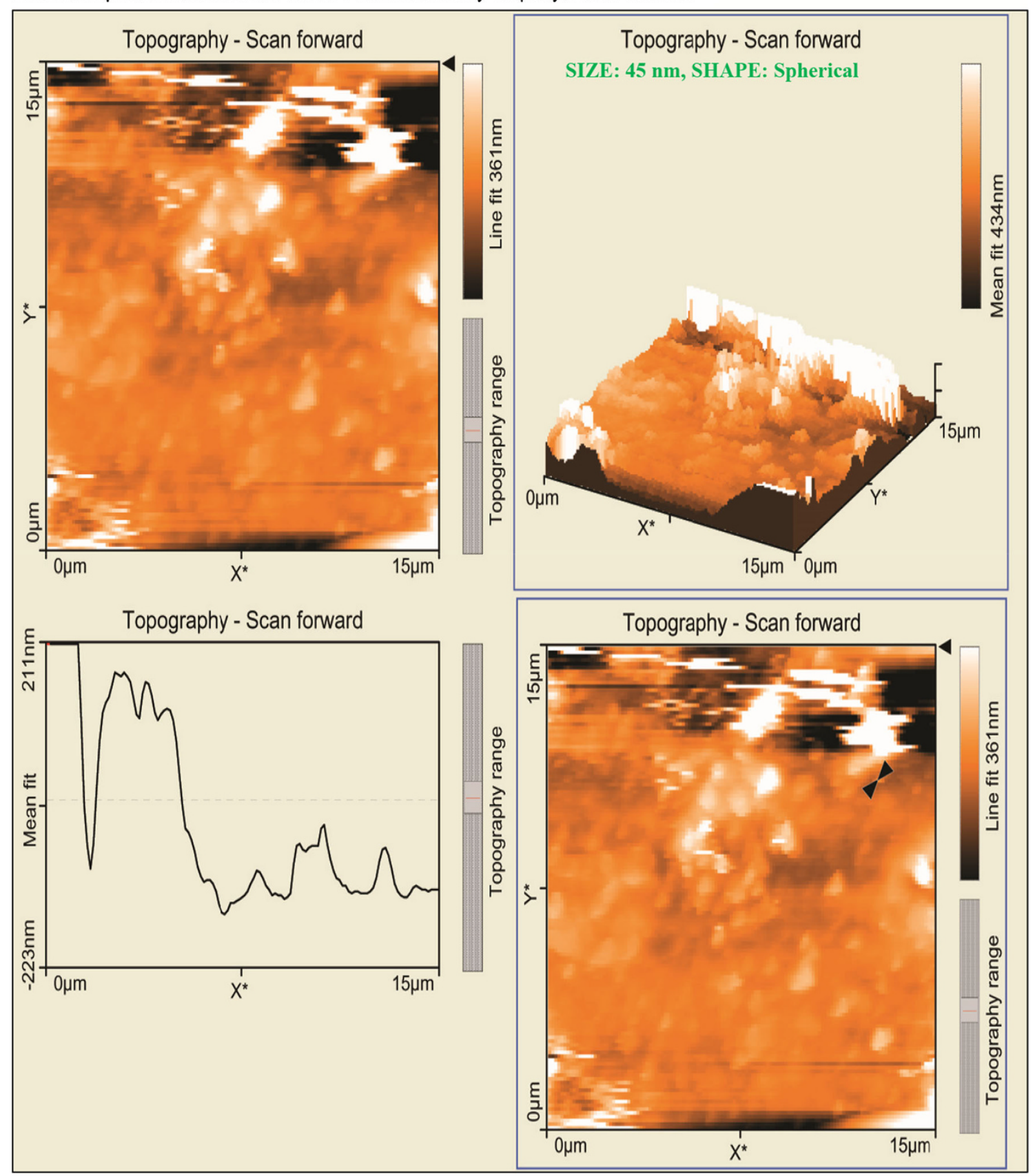

Fig. 6 AFM image detailing the topographical information of SNPS synthesized using the stem bark extract of Cochlospermum religiosum

reflections, respectively, in Fig. 3 are through to be related to crystalline and amorphous organic phases. It was found that the average size form XRD data and using the DebyeScherrer equation was approximately $28.64 \mathrm{~nm}$.

The SEM analysis was used to determine the structure of the reaction products that were formed. SEM image has showed individual silver particles as well as number of aggregates, SEM images of SNPs derived from the aqueous bark extracts of $C$. religiosum showed the particles in spherical shape and size ranged from 20 to $35 \mathrm{~nm}$ (Fig. 4). The morphology of the SNPs was predominantly spherical and they appear to be monodispersed. Further, analysis of the silver particles by energy dispersive spectroscopy confirmed the presence of the signal characteristic of silver (Fig. 5). All the peaks of Ag are observed and are assigned. Peaks of Ag are from the grid used and the peaks of S, P, and 
Fig. 7 FT-IR spectra representing the functional groups associated with the reduction and stabilization of Cochlospermum religiosum stembark-mediated silver nanoparticles

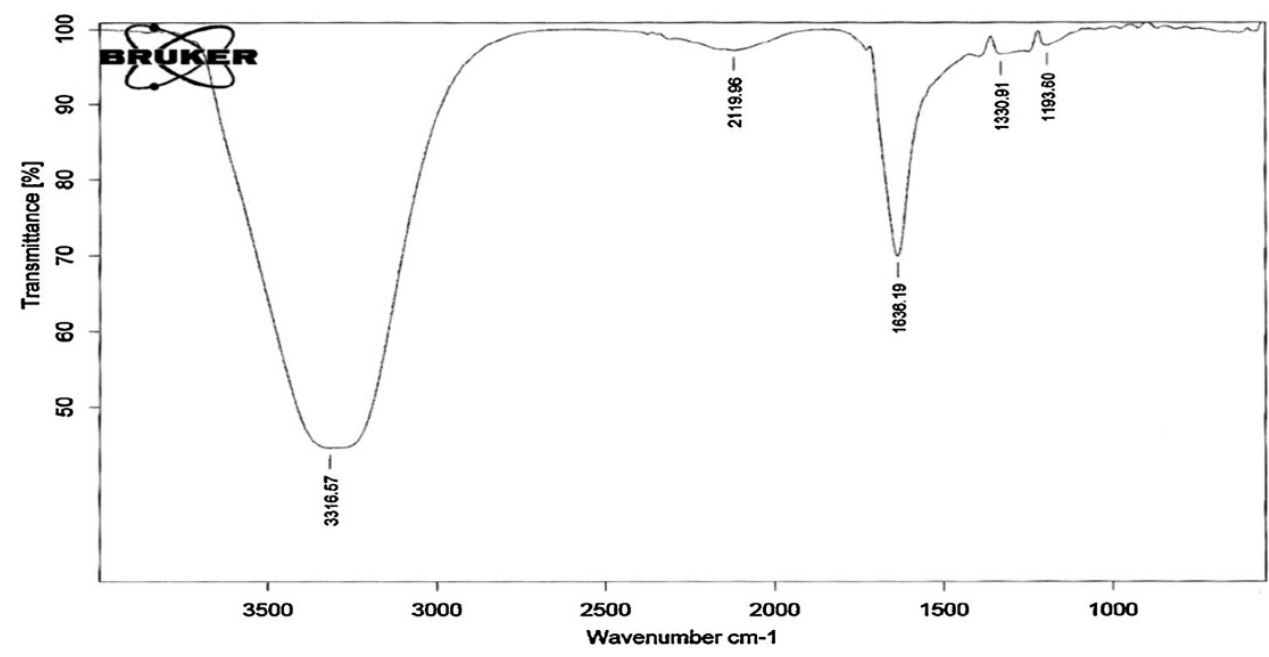

Table 1 Antimicrobial activity of stem bark aqueous extract and silver nanoparticles of C. religiosum

\begin{tabular}{|c|c|c|c|c|c|}
\hline \multirow[t]{2}{*}{ S. no. } & & \multirow[t]{2}{*}{ Standard (Streptomycin/Nystatin) } & \multicolumn{3}{|l|}{ C. religiosum } \\
\hline & & & Control & SNPs & $\mathrm{AgNO}_{3}$ \\
\hline \multicolumn{6}{|c|}{ Bacterial species } \\
\hline 1 & Proteus & $15.06 \pm 1.12$ & $6.28 \pm 0.10$ & $10.25 \pm 1.22$ & $11.14 \pm 1.82$ \\
\hline 2 & Pseudomonas & $17.28 \pm 0.20$ & $5.24 \pm 0.10$ & $15.25 \pm 1.20$ & $10.16 \pm 1.82$ \\
\hline 3 & Bacillus & $20.11 \pm 2.81$ & $3.24 \pm 0.32$ & $12.12 \pm 1.38$ & $15.16 \pm 1.21$ \\
\hline 4 & Staphylococcus & $25.00 \pm 4.12$ & $2.15 \pm 0.32$ & $18.18 \pm 1.30$ & $14.28 \pm 1.00$ \\
\hline 5 & E.coli & $15.28 \pm 2.11$ & $3.12 \pm 0.32$ & $15.18 \pm 1.32$ & $16.78 \pm 1.21$ \\
\hline \multicolumn{6}{|c|}{ Fungal species } \\
\hline 6 & Aspergillus flavus & $15.66 \pm 2.52$ & $4.24 \pm 0.11$ & $8.12 \pm 0.11$ & $11.12 \pm 1.81$ \\
\hline 7 & Aspergillus niger & $20.26 \pm 2.11$ & $5.24 \pm 0.28$ & $5.18 \pm 0.33$ & $10.12 \pm 1.20$ \\
\hline 8 & Curvularia & $17.05 \pm 2.11$ & $3.00 \pm 1.54$ & $6.10 \pm 0.57$ & $10.12 \pm 1.20$ \\
\hline 9 & Fusarium & $10.33 \pm 0.80$ & $4.41 \pm 0.21$ & $7.25 \pm 0.31$ & $9.80 \pm 0.31$ \\
\hline 10 & Rhizopus & $18.66 \pm 1.02$ & $4.24 \pm 1.28$ & $8.12 \pm 0.11$ & $11.12 \pm 1.81$ \\
\hline
\end{tabular}

\pm indicates standard deviation

$\mathrm{N}$ correspond to the protein capping over the AgNPs. EDAX information has given the various elements along with SNPs of bark extracts of $C$. religiosum was identified elements like $\mathrm{C}, \mathrm{O}, \mathrm{Mg}, \mathrm{Si}, \mathrm{Ag}$, and $\mathrm{Al}$ with different percentages.

AFM analysis the SNPs were clearly distinguishable owing to their size difference. An AFM image has given average sizes of SNPs of $C$. religiosum is $45 \mathrm{~nm}$ with three dimensional structures. SNPs attached with one another and look like a cluster in an area of $15 \mu \mathrm{m}$ with rod shape in 3D view (Fig. 6). The physicochemical properties of nanoparticles differ dramatically from fine particles of the same composition (Geraci and Castranova 2010).

The FTIR spectra Fig. 7 indicate different functional groups at various positions. The vibrational bands correspond to the bonds such as aminuteso $(\mathrm{N}-\mathrm{H}),-\mathrm{C}=\mathrm{C}$ (alkene), and $\mathrm{C}-\mathrm{Cl}$ (Halogens) which were in the region range of $1,194-3,315 \mathrm{~cm}^{-1}$. The most wide spectrum absorption was observed at $3,315 \mathrm{~cm}^{-1}$, it can be attributed to the stretching vibrations of aminuteso $(\mathrm{N}-\mathrm{H})$
(Maliszewska and Sadowski 2009) and absorption peaks observed at $1,636 \mathrm{~cm}^{-1}$ can be attributed to the stretching vibration of $-\mathrm{C}=\mathrm{C}$ (alkene) (Rajasekharreddy et al. 2010). This FT-IR spectroscopic study confirmed that the carbonyl group of amino acid residues has a strong binding ability with silver, suggesting the formation of a layer covering silver nanoparticles and acting as a capping agent to prevent agglomeration and provide stability to the medium. These results confirm the presence of possible proteins as reducing stabilizing agents.

The antimicrobial activity of silver nanoparticles was carried out against various pathogenic microbes such as gram negative and gram positive bacteria of Staphylococcus, E. coli, Proteus vulgaris, Pseudomonas aeruginosa, and Bacillus subtilis, fungal species of Aspergillus niger, Aspergillus flavus, Fusarium, Curvularia, and Rhizopus using disk diffusion method. The extraction without silver nanoparticles served as control. Bark aqueous extract of $C$. religiosum showed broad spectrum of antimicrobial 

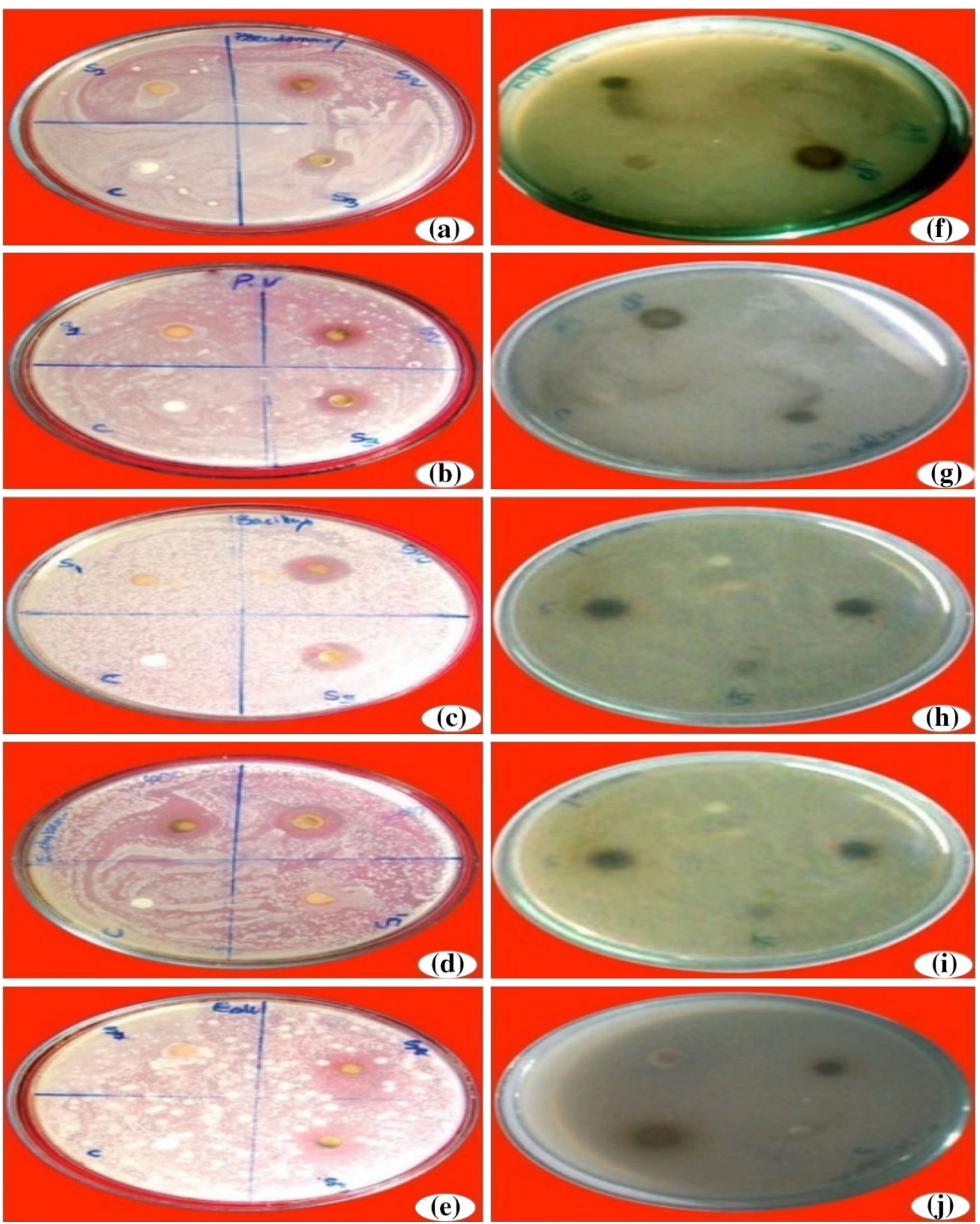

Fig. 8 Antimicrobial activity of biologically synthesized SNPs of stembark against a Bacillus, b E. coli, c Proteus, d Pseudomonas, e Staphylococcus, f Aspergillus flavus, g Fusarium, h Curvularia

lunata, $\mathbf{i}$ Rhizopus, $\mathbf{j}$ Aspergillus niger, 1 leaf extract, 2 leaf SNPs, 3 Silver nitrate, 4 Gentamycin/Nystatin

activity. The diameter of inhibition zone around each disk with SNPs is measured and each disk contains of $20 \mu \mathrm{l}$ of SNPs solution (Table 1). The SNPs of bark extract of $C$. religiosum showed highest antibacterial activity against Staphylococcus, followed by Pseudomonas, E. coli,

Bacillus, and lowest activity toward Proteus and maximum inhibition zone was observed against fungal species of Aspergillus flavus followed by Rhizopus, Fusarium Curvularia, and minimum inhibition zone was observed against Aspergillus niger (Figs. 8, 9).

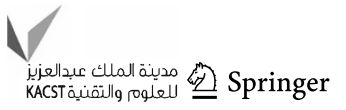




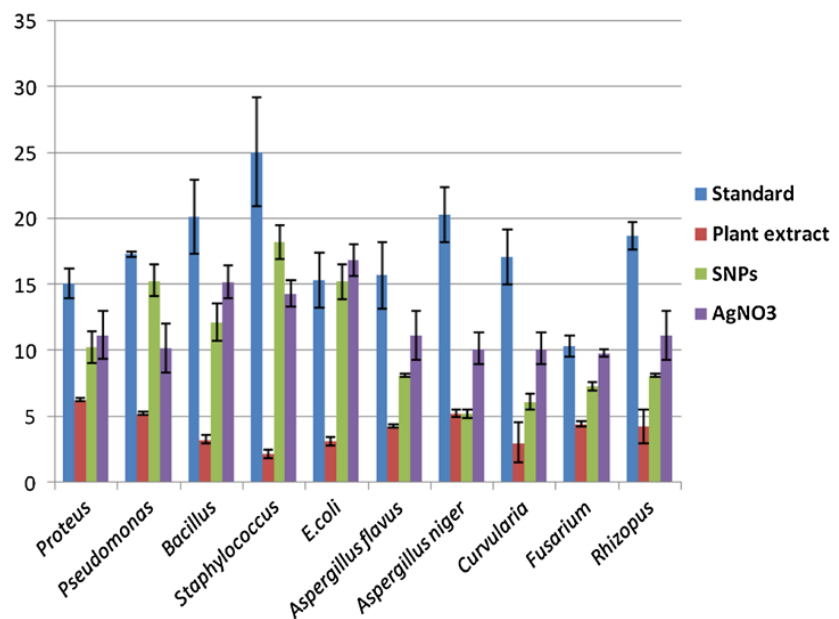

Fig. 9 Antimicrobial activity of stem bark aqueous extract and silver nanoparticles synthesized using C. religiosum

It is interesting to note that the SNPs synthesized via green route are highly toxic toward bacterial strains when compared to fungal strains. Silver ions have been demonstrated to interact with the protein and possibly phospholipids associated with the proton pump of bacterial membranes (Savithramma et al. 2012). These results in a collapse of membrane proton gradient causing a disruption of many of the mechanisms of cellular metabolism and hence cell death (Dibrov et al. 2002). Silver ions interact with a wide range of molecules processes within a micro organism resulting in a range of effects from inhibition of growth and loss of ineffectiveness. The mechanism depends on both the concentration of silver ions present and the sensitivity of the microbial species to silver. The spectrum of activity is very wide and the development of resistance relatively law (Cooper 2004). The use of plant extracts is effective against various microorganisms including plant pathogens (Mishra et al. 2007).

\section{Conclusion}

Stem bark extract of Cochlospermum religiosum was proved to be one of the potential sources to produce stable and well-defined nanoscale silver particles. Using medicinal plants and plant parts for the synthesis of metallic nanoparticles, silver in particular, has logical background for their use in therapeutic applications. The conjunctive effect of both silver nanoparticles and the medicinal biomolecules present on the surface of the silver nanoparticles was significant against an array of microbes as the bacterial and fungal strains are getting resistance to traditional and standardized drugs.
Acknowledgments Authors are thankful to DST for financial assistance and also thankful to SAIF, IIT Madras and VIT, Vellore for their help in equipments.

Open Access This article is distributed under the terms of the Creative Commons Attribution License which permits any use, distribution, and reproduction in any medium, provided the original author(s) and the source are credited.

\section{References}

Ankamwar B, Damle C, Ahmad A, Sastry M (2005) Biosynthesis of gold and silver nanoparticles using Emblica officinalis fruit extract, their phase transfer and transmetallation in an organic solution. J Nano Sci Nanotechnol 5:1665-1671

Ankanna S, Prasad TNVKV, Elumalai EK, Savithramma N (2010) Production of Biogenic silver nanoparticles using Boswellia ovalifoliolata stem bark. Digest J Nano Biostruct 5:369-372

Bauer AW, Kirby MDK, Sherri JC, Track M (1966) Antibiotic susceptibility testing by a standardized single disc method. Am J Clin Pathol 45:493-496

Bhumi G, Lingarao M, Savithramma N (2013) Biological synthesis of silver nanoparticles from stembark of Thespesia populnea (L.) soland. Indian Streams Res J 3:1-7

Cecilie SN, Drissa D, Kari I, Terje EM, Tsukasa M, Hiroaki K (2005) Medicinal use of Cochlospermum tinctorium in Mali Anti-ulcer, radical scavenging and immunomodulating activities of polymers in the aqueous extract of the roots. $\mathrm{J}$ Ethnopharmacol 96:255-269

Cheng Y, Yin L, Lin S, Wiesner M, Bernhardt E, Liu J (2011) Toxicity reduction of polymer-stabilized silvernanoparticles by sunlight. J Phys Chem C 115:4425

Cooper R (2004) A review of the evidence for the use of topical antimicrobial agents in wound care, worldwide wounds, p 88

Dibrov P, Dzioba J, Gosink KK, Hase CC (2002) Chemiosmotic mechanism of antimicrobial activity of $\mathrm{Ag}(+)$ in Vibrio cholerae. Antimicrob Agents Chemother 46:2668-2670

Geraci CH, Castranova V (2010) Challenges in assessing nanomaterial toxicology: a personal perspective reviews. Nanomed Nanobiotech 2(6):569-577

Goud PS, Murthy KS, Pullaiah T, Babu GV (2005) Screening for antibacterial and antifungal activity of some medicinal plants of Nallamalais-Andhra Pradesh, India. J Econ Taxono Bot 29:704-708

Hirsch T, Zharnikov M, Shaporenko A, Stahl J, Weiss D, Wolfbeis OS, Angew VM (2005) Size-controlled electrochemicalsynthesis of metal nanoparticles on monomoleculartemplates. Angew Chem Int Ed 44:6775-6778

Kim JR, Jung SH, Regan JM, Logan BE (2007) Electricity generation and microbial community analysis of alcohol powdered microbial fuel cells. Bioresour Technol 98:2568-2577

Linga Rao M, Savithramma N (2012) Antimicrobial activity of silver nanoparticles synthesized by using stem extract of Svensonia hyderobadensis (Walp.) Mold-a rare medicinal plant. Res Biot 3:41-47

Linga Rao M, Bhumi G, Savithramma N (2013) Green synthesize of silver nanoparticles by using Allamanda cathartica L. leaf extract and evaluation of their antimicrobial activity. Int J Pharm Sci Nanotechnol 6(4):2260-2268

Liu W, Wu Y, Wang C, Li HC, Wang T, Liao CY, Cui I, Zhou QF, Yan B, Jiang GB (2010) Impact of silver nanoparticles on human cells; effect of particle size. Nanotoxicology 4:319-330 
Logeswari P, Silambarasan S, Abraham J (2012) Synthesis of silver nanoparticles using the plants extract and analysis of their antimicrobial property. J Saudi Chem Soc. doi:10.1016/j.jscs. 2012.04.007

Maliszewska I, Sadowski Z (2009) Synthesis and antibacterial activity of silver nanoparticles. J Phys Conf Ser 146:012024

Mishra YK, Mohapatra S, Kabiraj D, Mohanta B, Lalla NP, Pivin JC, Avasthi DK (2007) Synthesis and characterization of Ag nanoparticles in silica matrix by atom beam sputtering. Scr Mater 56:629-632

Nagajyothi PC, Sreekanth TVM, Prasad TNVKV, Lee KD (2012) Green synthesis of silver and gold nanoparticles using Lonicera Japonica flower extract. Adv Sci Lett 5:124

Nestor ARV, Mendieta VS, Lopez MAC, Espinosa RMG, Lopez MAC, Alatorre JAA (2008) Solventless synthesis and optical properties of $\mathrm{AU}$ and $\mathrm{Ag}$ nanoparticles using Camiellia sinensis extract. Mater Lett 62:3103-3105

Plante IJL, Zeid TW, Yangab P, Mokari J (2010) Synthesis of metal sulfide nanomaterials via thermal decomposition of single-source precursors. Mater Chem 20:6612

Rajasekharreddy P, Rani PU, Sreedhar B (2010) Qualitative assessment of silver and gold nanoparticle synthesis in various plants: a photobiological approach. J Nano Res 12:1711-1721

Sasikala A, Savithramma N (2012a) In vitro plant regeneration of Cochlospermum religiosum through shoot tip culture. Res J Biot 7:78-81

Sasikala A, Savithramma N (2012b) Biological synthesis of silver nanoparticles from Cochlospermum Religiosum and their antibacterial efficacy. J Pharm Sci Res 4:1836-1839

Sasikala A, Savithramma N (2012) Phytochemical divaersity of Cochlospermum religiosum (L.) Alsten-a medicinal tree species. Threats Concerns Biodivers 50-59
Sasikala A, Lingarao M, Savithramma N (2013a) Quantification of primary and secondary metabolites from leaves and stembarks of Cochlospermum religiosum (L.) Aston. Int Res J Pharm 4:228-231

Sasikala A, Lingarao M, Savithramma N (2013b) Histochemical studies of Cochlospermum religiosum (L.) Aston. Weekly Sci Res J 1:1-7

Savithramma N, Lingarao M, Suvarnalatha Devi P (2011) Evaluation of antibacterial efficacy of Biologically synthesized silver nanoparticles using stem barks of Boswellia ovalifoliolata Bal. and Henry and Shorea tumbuggaia Roxb. J Biol Sci 11:39-45

Savithramma N, Lingarao M, Ankanna S, Venkateswarlu P (2012) Screening of medicinal plants for effective biogenesis of silver nanoparticles and efficient antimicrobial activity. Int J Pharm Sci Res 3:1141-1148

Shahverdi RA, Fakhimi A, Shahverdi HR, Minaian S (2007) Synthesis and effect of silver nanoparticles on the antibacterial activity of different antibiotics against Staphylococcus aureus and Escherichia coli. Nanomed Nanotech Biol Med. 3:168-171

Tian J, Wong KKY, Ho CM (2001) Topical delivery of silver nanoparticles promotes would heal. Chem Med Chem 2:129-136

Van der Plas MJ, Jukema GN, Wai SW, Dogterom-Ballering HC, Lagendijk EL, van Gulpen C, van Dissel JT, Bloemberg GV, Nibbering PH (2008) Maggot excretions/secretions are differentially effective against biofilms of Staphylococcus aureus and Pseudomonas aeruginosa. J Antimicrob Chemother 61(1):117-122

Venkateswarlu P, Ankanna S, Prasad TNVKV, Elumalai EK, Nagajyothi PC, Savithramma N (2010) Green synthesis of silver nanoparticles using Shorea tumbuggaia stem bark. Int J Drug Dev Res 2:720-723 